\title{
Missing Money and Missing Markets: Reliability, Capacity Auctions and Interconnectors ${ }^{1}$ \\ David Newbery ${ }^{2}$ \\ Energy Policy Research Group, University of Cambridge \\ 25 August 2015
}

\begin{abstract}
In the energy trilemma of reliability, sustainability and affordability, politicians treat reliability as over-riding. The EU assumes the energy-only Target Electricity Model will deliver reliability but the UK argues that a capacity remuneration mechanism is needed. This paper argues that capacity auctions tend to over-procure capacity, exacerbating the missing money problem they were designed to address. The bias is further exacerbated by failing to address some of the missing market problems also neglected in the debate. It examines the case for, criticisms of, and outcome of the first GB capacity auction and problems of trading between different capacity markets.
\end{abstract}

Keywords: capacity auctions, procurement, missing markets, interconnectors

\section{Introduction}

Britain was the first country to introduce a capacity auction to deliver capacity adequacy after the EU Third Package ${ }^{3}$ (to deliver the Target Electricity Model, TEM) was announced and it coincided with the date by which the TEM was to come into effect. The TEM is designed as an energy-only market that leaves the delivery of capacity adequacy to profit-motivated investment decisions by liberalized and unbundled generation companies. The UK’s Energy Act 2013 that set out the Electricity Market Reform (EMR) rejected relying on an energy-only market and legislated for auctions to deliver capacity adequacy.

This paper examines the design and justification of that capacity auction, its relation to the wider issue of reliability, and criticizes the under-studied issue of how the amount of capacity to procure was determined. It argues that typical capacity auction designs have a bias towards excess procurement, in contrast to fears that the energy-only market would lead to under-procurement. While capacity remuneration mechanisms, of which auctions are potentially the best, are intended to address the missing money problem, by ignoring the missing market problem they perversely exacerbate the missing

\footnotetext{
${ }^{1}$ Paper arising from the Symposium on Energy Markets and Sustainability, Barcelona, 3 Feb. 2015

${ }^{2}$ Faculty of Economics, University of Cambridge, Email dmgn@cam.ac.uk, +44 1223335248. The author is a member of the Panel of Technical Experts advising DECC on the delivery of Electricity Market Reform but this article is written entirely in his personal academic capacity, drawing solely on published material. I am indebted to two excellent referees.

${ }^{3}$ See e.g. http://www2.nationalgrid.com/UK/Industry-information/Europe/Third-energy-package/
} 
money problem. Capacity auction design also raises important questions for cross-border trading and the role of interconnectors, which this paper addresses. It argues that it is less important to harmonize capacity remuneration mechanisms than to ensure that trade between countries is governed by clear market signals or clear out-of-market agreements between System Operators (when markets reach price caps or otherwise fail), without the fear of political or regulatory over-rides in stress situations. This may require reforms to the Security of Supply Directive (2005/89/EC). Given confidence in these stress allocation mechanisms, countries have an incentive to address market failures and ensure efficient trade.

Capacity adequacy is the ability "to supply the aggregate electrical demand and energy requirements of the end-use customers at all times, taking into account scheduled and reasonably expected unscheduled outages of system elements" (NERC, 2015). The reliability of an electricity system also requires security: "The ability to withstand sudden disturbances, such as electric short circuits or unanticipated losses of system components ...” (ENTSO-E, 2015). ${ }^{4}$ Security is a public good supplied by the System Operator (SO) through his acquisition of a range of ancillary and balancing services, while adequacy could, in principle, be delivered by competitive energy-only markets, as the TEM envisages (Oren, 2000).

The core of the TEM is an energy-only market with a single auction platform, EUPHEMIA (Pan-European Hybrid Electricity Market Integration Algorithm) which simultaneously clears bids and offers and the use of all interconnectors across the EU, fragmenting the market into different price zones only after interconnectors are fully used. Its working hypothesis, that energy-only markets will deliver capacity adequacy, was based on the experience of Nord Pool, which served as the model for the TEM.

Nord Pool has operated a successful energy-only trading system for many years, as have the major power exchanges such as EEX and APX, without any apparent problems of capacity adequacy, but not all EU countries have (or once) followed this model. Many markets have made or continue to make capacity payments, and DG COMP has been very critical of this practice, arguing that they often have more to do with compensating generators for stranded assets than delivering reliability at least cost. The GB capacity market is, ${ }^{5}$ as of mid-2015, the only capacity market to be explicitly designed and operating since the announcement of the Third Energy Package.

As a number of countries are now considering whether, and if so how, to introduce a (or reform their) Capacity Revenue Mechanisms it is timely to examine the British experience. Eurelectric is the latest organization to recognize that not all EU countries will be happy with the reference energy-only markets of the TEM, and "recognizes that properly designed capacity markets, developed in line with the objective

\footnotetext{
${ }^{4}$ Bompard et al (2013) provides a useful taxonomy of terms used to describe security.

${ }^{5}$ Northern Ireland is part of the SEM discussed below, leaving Great Britain, GB, as the rest of the UK.
} 
of the IEM, are an integral part of a future market design.” (Eurelectric, 2015, p4.) While that document discusses what might be required to deliver a reliability standard, it is somewhat sceptical on how this might be achieved, instead arguing that "whatever reliability standard is chosen, Regulators and TSOs should compute it with methodologies and tools that are publicly available." A second objective of this paper is to assess how this might best be done, guided by the principle of addressing the missing market problem.

\section{Missing money and missing markets}

While ensuring short-term security of supply is normally the duty of the SO, capacity adequacy is often the subject of regulatory and political concern. EU electricity markets are now liberalized and generation is, for the most part, not regulated but subject, like other industries, to normal competition policy. If markets were not subject to policy interventions or price caps, it is plausible that capacity adequacy could be delivered by profit-motivated generation investment without explicit policy guidance. For this to be the case, investors need confidence that the revenue they earn from the energy markets (including those supplying the ancillary services that the SO needs to ensure short-term stability) will be adequate to cover investment and operating costs.

If this revenue is not adequate, there is a "missing money" problem (Joskow, 2013), but if it is potentially adequate but not perceived to be so by generation companies or their financiers, then there is a "missing market” problem (Newbery, 1989). Missing money problems arise if price caps are set too low (below the Value of Lost Load, VoLL), or ancillary services, such as flexibility, ramp-rates, frequency response, black start capability, etc. and/or balancing services are inadequately remunerated, and/or energy prices are inefficiently low. Inefficiently low wholesale prices seem less likely as the normal problem is one of market power raising prices above their competitive level, and prices are not necessarily inefficiently low just because there is excess capacity.

Missing markets create problems if risks cannot be efficiently allocated with minimal transaction costs through futures and contract markets, or if important externalities such as $\mathrm{CO}_{2}$ and other pollutants are not properly priced. The concept of missing markets can be usefully extended to cases in which politicians and/or regulators are not willing to offer hedges against future market interventions that could adversely affect generator profits. The various arguments for capacity markets have been extensively covered in the literature, recently in the Symposium on 'Capacity Markets', (Joskow, 2013; Cramton et al., 2013). Almost all the discussion about capacity mechanisms concentrates on the missing money problem and whether the various market and regulatory/political failures are sufficient to justify a capacity mechanism, and if so, what form it should best take. ${ }^{6}$

\footnotetext{
${ }^{6}$ See e.g. Adib et al. (2008), Batlle et al. (2007), Battle and Rodilla (2010), Bowring (2008, 2013), Chao and Wilson (1987, 2002), Crampton and Ockenfels (2011), Cramton and Stoft
} 
Both the missing money and missing market failures have risen in salience as renewable electricity targets have become more ambitious at the same time as the EU Emissions Trading System has failed to deliver an adequate, durable and credible carbon price, and as such is under constant threat of reform. Absent a futures market with a credible counter-party it is hard to be confident that future electricity prices will be remunerative for unsubsidized generation, and harder to convince bankers or shareholders of the credibility of investment plans based on forecast revenues. If renewables continue their planned increase in market share mandated by the EU Renewables Directive (2009/28/EC) they will depress average energy prices. This does not of itself give rise to an adequacy problem, although utilities may justifiably complain that their past investment decisions have been partially expropriated by unanticipated political actions. However, it increases the demand for existing balancing services such as primary reserves, fast frequency response and inertia and may also increase the need for additional ancillary services. If these services are not yet adequately defined and/or their future prices are hard to predict there is a missing market problem. If these services are underpriced by SOs whose powers of balancing supply and demand may be met by administrative or regulatory means (e.g. by requiring those connecting to the grid to make some of these services available as part of the grid code), there is a missing money problem. In either case these may precipitate a capacity adequacy problem.

\subsection{Market failures in delivering reliability}

Before the electricity industry was liberalized and unbundled, the SO had ownership control of generation and transmission and was responsible for both system security and adequacy. Planned investment ensured that both capabilities would be assessed, which was also much easier when essentially all plant had (at least in aggregate) a predictable and controllable output. The main security problem to address was very short-run increases in demand (notably during intermissions in major sporting events when consumers all simultaneously switch on their electric kettles) or those caused by the loss of a large station or transmission link. This was addressed by specifying a reserve margin and ensuring adequate short-run flexibility by the choice of plant type. Thus the Central Electricity Generating Board, CEGB, that pre-dated the British restructuring of 1989, computed the required gross reserve margin at $19 \%$ based on a Loss of Load Probability (LoLP) calculation and a reliability measure (disconnecting some consumers in three winters over a 100 years, decided in 1962 (Bates and Fraser, 1974, p122)). It built pumped storage systems to provide fast response peaking capacity and to use surplus night-time nuclear power (Williams, 1991), as well as jet-derivative gas turbines for fast ramping.

(2008), Joskow (2008), Joskow and Tirole (2007); O’Neill at al. (2006); Platchkov et al (2011); and de Vries (2007). 
With liberalization and unbundling all these security services had to be separately procured by the SO. Some, such as inertia and the additional security offered by interconnectors, came at no cost to the SO. Others had to be procured through balancing and contract markets, just when the challenges of handling increasing volumes of intermittent and less predictable wind were increasing (Newbery, 2010, introducing "Large-scale wind power in electricity markets" in that issue of Energy Policy; Newbery, 2012b). As problems of intermittency increase, so does the challenge of ensuring that these services are efficiently priced and procured (Pöyry, 2014).

The Single Electricity Market (SEM) of the island of Ireland is probably at the forefront of addressing these problems, as it is a small moderately isolated system in which individual power stations are large and lumpy relative to peak demand (up to $10 \%$ ) and the system is being adapted to handle up to $70 \%$ non-synchronous wind penetration. ${ }^{7}$ One (implausible) solution would have price signals varying over very short periods of time. A sudden fall in frequency caused by a sudden fall in supply relative to demand means that the value of power in the next cycle $\left(1 / 50^{\text {th }}\right.$ of a second) has increased, and the speed of response is key to minimizing the disruption. Fast responders would enjoy the sudden increase in price which slower responders would miss.

Figure 1 lists the various products and their time domain that the SEM Committee defined in their consultation document (SEM, 2014), grouped into the three categories of Synchronous Inertial Response (SIR, usually delivered by the inertia of synchronized generators), operating reserves (primary, POR; secondary, SOR; and tertiary, TOR), and Ramping or Replacement Reserves (RR), with some overlap between them.

If prices were to move in response to instantaneous system conditions, then it would be potentially profitable to have the capability to respond on the appropriate time scale. In practice, market designs vary in their granularity, with the most flexible having 5 minute settlement periods (Australia). Some Continental balancing markets have a 15 minute settlement period, ${ }^{8}$ while GB and the SEM have a half-hourly settlement period in the Day Ahead Market (DAM), and most Continental power exchanges and the EUPHEMIA auction platform have hourly resolution in the DAM. Increasing granularity improves the accuracy of the temporal pattern of price signals to guide the choice of flexibility, but runs up against the practical constraint that the system state requires a finite amount of time to re-estimate, probably of the order of minutes, while the transaction costs of dealing at high frequency make very short-term markets illiquid.

Given the inability and absence of energy markets at this level of time granularity, new products are needed to supplement existing products. The SEM Committee consulted on how to procure them in early 2015, given that the supply side for some

\footnotetext{
${ }^{7}$ Conventional rotating generation turbines are synchronised to the grid frequency and have substantial inertia, so that if there is a momentary loss of supply, that inertia prevents the frequency falling too fast. Wind power has effectively no inertia, which has to be provided in some form to maintain frequency within acceptable limits.

${ }^{8}$ Also suggested by Mott MacDonald (2013). California is interested in 5 minute granularity.
} 
services is highly concentrated, raising market power issues. In this case many markets are missing as their procurement is still undecided, making it hard to estimate their future revenues. When choosing what type of generating plant to build, investors have a choice of characteristics with inevitable trade-offs: flexible plant with high ramp rates is either more expensive or less efficient than less flexible plant with lower ramp rates, but unless investors can forecast the revenue from selling these security services, it is hard to make efficient plant choices.

The classic public good problem facing the regulators and the SO is how to value these various services, given that they are provided in bundles of varying proportions by different technologies. Some of the services reduce LoLP, and should be informed by the VoLL, but others reduce the need to curtail renewable generation, which is a political objective of uncertain value.

\subsection{Defining and measuring reliability}

Eurelectric (2015) provides a useful summary of the various ways used to measure reliability. Most EU electricity systems specify the "Loss of Load Expectation” (LoLE), which for most and for GB is three hours per year. Averaging over a large number of possible events (cold weather, plant failures, high demand, etc.) for some future period, the electricity system should perform better than averaging "Losses of Load events" of three hours per year. Clearly there is a difference between losing load for the entire population and controlled disconnections for a modest number of consumers, and Eurelectric (2015) argues that a better measure is the Loss of Expected Energy (LoEE) or Expected Energy Unserved (EEU) measured in MWh/year. National Grid (2014a) uses the cost of EEU to determine the procurement amount for the capacity auction.

The former CEGB had a standard of disconnections in three winters in 100 years or $3 \%$, while Belgium had a $1 \%$ standard and Spain a 5\% standard (Webb, 1977). This was often translated into a gross reserve margin (Transmission Entry Capacity less peak load) required to deliver the reliability standard. Thus the CEGB set it at $19 \%$, made up of a de-rating factor of $11 \%$ and remaining outage risks of $6 \%$, so that the de-rated reliability margin was $7 \%(6 \% / 0.89)$. Such quantitative measures sit well within the planning framework of a centrally controlled electricity system pre-liberalization.

The other more market-oriented approach to reliability is to specify the Value of Lost Load, VoLL, the amount that consumers should be willing to pay to avoid disconnection. In a future with sufficiently smart meters, consumers would be able to sign a contract with the electricity supplier stating the maximum amount they would be willing to pay for each tranche of firm power, with the smart meter disconnecting appliances at each specified price point, leaving some lights, television and electronic equipment until last. That would create the currently largely absent demand side and provide a private good market solution to the problem. It could avoid the missing money if not the missing (future) market problem, provided the short-run prices were set at their 
efficient scarcity value. This is the sum of the System Marginal Cost (SMC) plus a Capacity Payment, CP, where

$$
\mathrm{CP}=\mathrm{LoLP} *(\mathrm{VoLL}-\mathrm{SMC})
$$

The relationship between the security standard and the VoLL is symmetric, in that if capacity investment decisions are based on revenues determined by (1) and the VoLL is pre-determined, then the resulting capacity will give rise to a LoLE. If the standard is a predetermined LoLE, the cost of new capacity implies a cost of delivering the LoLP and hence an implied VoLL.

Britain has followed both models. The English Pool from 1989 to 2001 set the VoLL at $£(2012) 5,000$ (€6,250)/MWh, letting the market determine capacity. After the Pool was replaced with an energy-only market in 2001, the Department of Energy and Climate Change (DECC) specified the LoLE. National Grid (2014a) deduced the 2018 VoLL as $£(2012) 17,000 / \mathrm{MWh}$ ( $€(2012) 21,250 / \mathrm{MWh})$, higher than direct estimates of the willingness to pay to avoid disconnections (London Economics, 2013).

\subsection{Can energy-only markets deliver adequate reliability?}

One completely legitimate case for a capacity payment is that if generators are required to bid their Short Run Marginal Cost (SRMC, mostly fuel costs), as under the Bidding Code of Practice of the SEM (SEM, 2007), they will fail to recover their fixed costs without such an addition. The Electricity Pool of England and Wales also added the CP of (1), but allowed generators to offer an unrestricted supply function (which, given their market power, was often above SRMC, Green and Newbery, 1992; Newbery, 1995; Sweeting, 2007). In this period of benign liberalization, high electricity prices and low gas prices led to considerable entry and an excessive reserve margin.

In the energy-only market envisaged by the TEM, generators will offer supply functions that should reflect the scarcity value of electricity (and their degree of market power). Figure 2 shows the day-ahead price duration curves for several European power exchanges in 2012. What is striking is that most exchange prices do not exceed $€ 200 / \mathrm{MWh}$, and even the most peaky, France, only does so 0.25 of $1 \%$ of the time (about 22 hours per year). Given that the VoLL in the English Pool until 2001 was $€(2012) 6,250 / M W h$ and the current implied VoLL in GB is $€(2012) 21,250 / M W h$, these prices indicate a low LoLP or high reliability. Given existing capacity levels that is a reasonable inference, but the problem again is one of missing (futures) markets. Investment lags in delivering capacity adequacy are 2-4 years for peaking plant (longer for most base-load plant), beyond the time horizon of adequately liquid futures markets (and they only offer one year's hedge). 
On the other hand, Figure 3 shows that the 2008 balancing buy prices ${ }^{9}$ in the energy-only market that replaced the Pool were considerably peakier than the old Pool prices (which included an explicit CP and also probably reflected more market power). Thus energy-only markets can reflect scarcity, and properly calculated capacity payments may be very low if the reserve margin is adequate, as LoLP is roughly exponential in demand less de-rated capacity (Newbery, 2005). However, by 2013-14, the GB Balancing Mechanism had a price duration curve quite similar to those shown in Figure 2 , with prices above $€ 200 / \mathrm{MWh}$ for less than 0.25 of $1 \%$ of the time, and well below the French day-ahead price duration curve.

Thus one might conclude that energy-only markets (which include balancing markets) can deliver sufficiently sharp scarcity prices that should signal the profitability of adequate new investment, provided all the other security services are adequately remunerated (i.e. resolving any of those missing market problems). This might be plausible if all investment decisions were taken on commercial grounds as in the 1990s, that prices were not capped, that the policy environment were predictable and stable, and that either liquid forward market existed for a reasonably fraction of the proposed plant life (i.e. 20+ years ahead of the final investment decision) or credible long-term power purchase agreements could be signed with credit-worthy counterparties. Unfortunately, hardly any of these conditions hold in the TEM.

\subsection{Market, institutional and political/regulatory failures}

While price caps are set at rather low levels in the U.S., exacerbating the "missing money" problem, there are also, if much higher, price caps in EUPHEMIA (for dayahead at $€ 3,000 / \mathrm{MWh}$, a price that France has hit on numerous occasions). The lack of forward markets and long-term contracts might not be so critical if the future were reasonably predictable and stable, but this is far from the case at present. EU Climate Change policy is failing, in conflict with Renewables Directive (2009/28/EC), and surely ripe for as yet uncertain reform. Large volumes of unreliable renewables increase the need for flexible reserves, which in the past came from obsolescing plant, mostly oil or coal. This plant is now being decommissioned because of the Large Combustion Plant Directive and the Integrated Emissions Directive.

Increasing volumes of renewables (mainly wind and solar PV) add little to reliable capacity, as it is unavailable on still cold dark winter nights, but reduces average wholesale prices. If the average capacity factor of on-shore wind is $25 \%$, then the GB target of $30 \%$ of electricity from wind requires capacity of $30 / 25$ times or $120 \%$ of average demand. In windy conditions that would often displace all conventional plant and could lead, under present subsidy structures, to negative prices.

Intermittent generation increases the need for additional flexible plant that can be called up at short notice if the wind falls or the sun fades. In addition, new plant will be

\footnotetext{
${ }^{9}$ For a description of the British Balancing Mechanism see Newbery (2005).
} 
needed to replace retiring plant (not just coal, but in the UK, France and Germany, substantial volumes of nuclear plant as well). That plant will need considerably higher prices than recently experienced to be profitable. The EU is committed to an $80 \%$ reduction in Greenhouse Gas emissions by 2050. Coal is twice the carbon intensity of gas, so utilities are unlikely to build durable (40-60 years) coal-fired plant that would face tight future emissions limits, leaving gas-fired plant as the only alternative.

Unfortunately, crashed electricity prices and high gas prices precipitated by the closure of Japan's nuclear fleet made their economics very unattractive.

The UK introduced a carbon price floor in the 2011 Budget (HMT, 2011) that would support the price of $\mathrm{CO}_{2}$ at $£ 16 /$ tonne in 2013 , rising to $£ 30 /$ tonne ( $€ 35 /$ tonne) in 2020, and projected to rise to $£ 70 /$ tonne by 2030 (all at 2009 prices). As an example of policy instability, the 2014 Budget froze the carbon price floor - clearly an instrument subject to the whim of chancellors creates additional investment uncertainty. It would be a brave politician who trusted these markets to deliver reliability.

\section{The UK Electricity Market Reform and the capacity auction}

The UK led the European move to liberalized unbundled electricity markets by restructuring and privatizing most of the electricity supply industry in 1989. The generation companies inherited aging coal plant delivering $76 \%$ of output, with nuclear power $22 \%$ of the total and gas zero. By 2000 , nuclear still provided $22 \%$, but after the "dash for gas" new efficient combined cycle gas turbines (CCGTs) contributed 35\%, displacing coal whose share had fallen to $41 \%$. Non-thermal renewables accounted for just $2 \%$ of the total (DECC, 2015).

Newbery (2012a, 2013) documents the analysis that led to the UK's Electricity Market Reform (EMR) and its embodiment in the Energy Act 2013. Briefly, in response to the consultation on the Renewables Directive (2009/28/EC), the UK Government accepted one of the most challenging renewables targets (relative to its initial position) of $15 \%$ and promised to source $40 \%$ of electricity from low carbon sources and around $30 \%$ of electricity from renewables by 2020 (DECC, 2009). These ambitious targets undermined confidence that there would be any support for conventional generation, much of which was due to retire as a result of the EU Large Combustion Plant Directive (LCPD) and the EU Industrial Emissions Directive. Between 2008 and 20146 GW of coal plant closed, and $1.9 \mathrm{GW}$ converted to biomass, reducing total coal capacity by 8 GW (out of a total non-renewable capacity in 2008 of $69 \mathrm{GW}$ ). In addition $1.6 \mathrm{GW}$ of nuclear power and $2.8 \mathrm{GW}$ of large oil-fired capacity closed, or in total $10.4 \mathrm{GW}$, with more expected to exit before 2016. ${ }^{10}$ By 2014 nuclear's share of output had fallen to

\footnotetext{
${ }^{10}$ National Grid provides annual updates of the capacity and fuel of every grid-connected generator in its Electricity Ten Year Statements (and earlier Seven Year Statements) at http://www2.nationalgrid.com/UK/Industry-information/Future-of-Energy/Electricity-Ten-YearStatement/
} 
$18 \%$, gas to $29 \%$, but coal held up at $39 \%$ as coal and carbon prices fell, and renewables rose to $13 \%$ (DECC, 2015).

Faced with concerns over security of supply, the regulator, Ofgem, launched Project Discovery in June 2009. Ofgem's predicted de-rated capacity margin fell below 5\% by 2015 except under an optimistic “dash for energy” scenario (Ofgem, 2010, p40), and so Ofgem concluded that "(T)he unprecedented combination of the global financial crisis, tough environmental targets, increasing gas import dependency and the closure of ageing power stations has combined to cast reasonable doubt over whether the current energy arrangements will deliver secure and sustainable energy supplies.” (Ofgem, 2010).

Ofgem's Electricity Capacity Assessment Report 2014 confirmed these predictions, noting that the de-rated capacity margin could vary between $2 \%$ and $8 \%$ in 2015/16, and that the LOLE could, in response to the falling margin, increase to a maximum of 9 hours in 2015/16. Ofgem also noted that without reforms to the balancing mechanism, "the likelihood of controlled disconnections would vary between about 1 in 8 to 1 in 4 years in 2015/16 ... However, if National Grid procured the maximum volume of new balancing services it has indicated for 2015/16, the additional measures would reduce the risk of disconnections to up to around 1 in 73 to 1 in 31 years...” (Ofgem, 2014, p8). The consequential Expected Energy Unserved (EEU) for 2015/16 varied between 198 MWh to 20,864 MWh. To put these numbers in perspective, the highest EEU is less than 0.01 of $1 \%$ of annual demand, and if it corresponded to 9 hours of Loss of Load events, it would still represent full disconnection for only $4 \%$ of total load in those 9 hours.

DECC responded to Project Discovery with a similar diagnosis (DECC, 2010). Renewable electricity suffered from both the missing money and missing market problems, as support was provided by Premium Feed-in Tariffs via Renewable Obligation Certificates (ROCs). Their value depends on future electricity prices and the supply-demand balance for the ROC s, both potentially volatile. While fossil generation enjoyed a natural hedge as electricity prices mirror fossil fuel prices (Newbery, 2013, fig 2 ), renewables and nuclear power, whose fuel costs are zero or very small, are exposed to the full volatility of electricity prices (Roques et al., 2006; 2008). This increases risk and hence raises the cost of capital, the major part of the total cost.

The ensuing Energy Act 2013 (gradually) replaces volatile ROCs with long-term fixed-price Contracts-for-Differences (CfDs) for zero-carbon generation to solve both the missing money and the missing futures market problems. An Emissions Performance Standard rules out new unabated coal plant, and acts as a back-stop to the less credible Carbon Price Support (a tax to bring the EU carbon price up to the projected carbon price floor), while a Capacity Mechanism addresses the issue of capacity adequacy. Britain now has the Secretary of State for Energy \& Climate Change, advised by DECC, deciding how much capacity is required. The capacity auction is a single-price 
descending clock auction with a demand schedule as shown in figure 4. National Grid as SO was charged to recommend the target volume of capacity to secure four years after the auction (which was termed the T-4 auction).

National Grid (2014a) chose the amount to procure balancing the cost of additional capacity against the cost of the Expected Energy Unserved, as shown in Figure 5. National Grid (2014a) projected that the auction clearing price would likely be set at the net Cost of New Entry (CONE), estimated at $£ 49 / \mathrm{kWyr}$. This was the missing money a Combined Cycle Gas Turbine (CCGT) might need given its revenues from all other markets and after paying the Transmission Network Use of System (TNUoS) charges. These range from $£ 30 / \mathrm{kWyr}$ (in NW Scotland), to negative (-£5/kWyr in Cornwall) (National Grid, 2013) and are designed to guide new generation to where most needed. Entrants are given 15-year indexed contracts, while existing plant receive one-year contracts to defer exit decisions until the next auction.

The missing money can be roughly estimated from the VoLL ( $£ 17 / \mathrm{kWh})$ less the maximum the SO pays for balancing actions ( $£ 6 / \mathrm{kWh}$ ) to give $£ 11 / \mathrm{kWh}$, times $3 \mathrm{hrs}$ LoLE, or $£ 33 / \mathrm{kWyr}$. The effective cap in the Balancing Mechanism of $£ 9,999 / \mathrm{MWh}$ would reduce the missing money to $£ 21 / \mathrm{kWyr}$. Both numbers suggest a net CONE of $£ 49 / \mathrm{kWyr}$ is high or that other energy services are under-rewarded.

The auction design was best-practice (Newbery and Grubb, 2015) but flawed in requiring the SO to advise the minister on the procurement amount. The SO stands accountable if "the lights go out" but does not pay for the capacity. The minister wishes to avoid newspaper headlines predicting blackouts resulting from his decision. Both argue for excess procurement. DECC appointed an independent Panel of Technical Experts (PTE) to comment on the analysis, and they made a number of strong (but, for the 2014 auction, ineffective) criticisms.

\subsection{Criticisms of the capacity to procure}

The PTE first criticized the terminology of "Loss of Load" as emotive and misleading. The GB regulator, Ofgem, defines a "Loss of Load event" as one in which market demand exceeds market supply and as such the SO has to intervene to balance the system. For that purpose the SO can call on a range of increasingly expensive options: asking generators to temporarily exceed rated capacity; invoking 'new balancing services'; ${ }^{11}$ cutting interconnector exports to zero; requesting imports; reducing voltage ("brown outs"), ${ }^{12}$ before finally resorting to selective disconnections. The crucial point is that these actions cost less, often much less, than VoLL and hence bias the unserved load cost and the target capacity in figure 5 upward.

11 "The new balancing services are Demand Side Balancing Reserve (DSBR) and Supplemental Balancing Reserve (SBR).” National Grid announced its tender for these new services on 10 June 2014 (http://www.nationalgrid.com/uk/electricity/additionalmeasures ).

${ }^{12}$ The CEGB estimated that voltage reductions reduce load by $7 \frac{1}{2} \%$ in the 1970 s (Bates and Fraser, 1974) but National Grid now estimates only $1 \frac{1}{2} \%$ in the absence of firm evidence. 
Successful Capacity Market Units in the auction receive a Capacity Agreement which requires them to be available in "stress events" signaled four hours ahead. DECC (2014c, §391) defines these events as "any settlement periods in which either voltage control or controlled load shedding are experienced at any point on the system for 15 minutes or longer. ... Periods of voltage control or load shedding resulting from failures or deficiencies in the transmission or distribution systems are not considered as stress events." However, these "notices of inadequate system margin" are issued "based on the available capacity (declared 'maximum export limit' (MEL) minus transmission system demand and reserve for response capacity).” DECC (2014c, box, p107.)

National Grid (2014a) chose the amount to procure using a Least Worst Regrets approach as it was unwilling to attach explicit probabilities to the various scenarios considered. The result of overvaluing the cost of "Loss of Load" is to increase the capacity at which the Least Worst Regret cost schedule is minimized (figure 5). "Slow progression" reaches a cost minimum at $53.3 \mathrm{GW}$ for 2018-19 delivery. The net procurement target is 53.3-w- $x-y-z-0.4 \mathrm{GW}$, where $w, x, y$ and $z$ refer to various distributed energy resources and opt-out plant. The $0.4 \mathrm{GW}$ is existing short-term operating reserve.

The PTE (DECC, 2014a) strongly criticized National Grid for assuming no net imports in stress periods, despite $3.75 \mathrm{GW}$ interconnection capacity and potential new interconnector capacity of $2.25 \mathrm{GW}$ that might be available by 2018-19. This seemed perverse, as all parties (Ofgem, DECC and National Grid) agreed interconnectors increased security. Three reports commissioned by these parties (Pöyry, 2012, 2013; Redpoint, 2013) argued that interconnector capacity could displace domestic capacity by 50-80\% of its value. Even DECC's Final Impact Assessment, published just before the procurement decision (DECC, 2014b), estimated the amount of interconnector capacity to include in the total procurement amount at $2.9 \mathrm{GW}$. Ignoring interconnectors could move the auction clearing price from the net cost of new entry of $£ 49 / \mathrm{kWyr}$ to that set by existing plant (maximum of $£ 25 / \mathrm{kWyr}$ ), increasing the expected cost of procurement by $£ 1.3$ billion per year for the following 15 years.

Ignoring interconnectors seemed particularly perverse as the TEM aims to integrate markets across borders. Market coupling already dispatches GB Continental interconnectors in the EUPHEMIA day-ahead market (DAM). Interconnector flows already reflect willingness to pay in the DAM, and will soon do so in the intra-day and real time markets when network codes are agreed.

\subsection{Possible consequences of excessive capacity procurement}

Excess procured capacity will lower future wholesale prices with a number of effects, not all immediately obvious. First, lower prices reduce the revenue new entrants can expect from the energy markets, increase the net CONE and raise the auction price. Second, it undermines the old market design in which investment in conventional generation was at 
the discretion of private companies making commercial decisions. No company would invest in conventional generation without a capacity agreement given its large disadvantage compared to those with agreements. The amount of new plant will therefore be entirely determined by the minister, ending a key element of the liberalized market. All non-fossil generation will also be granted long-term CfDs under the EMR, moving Britain to the Single Buyer model ruled out in earlier EU Electricity Directives.

Third, lower prices increase payments to low-carbon CfDs, which receive the difference between the contracted strike and wholesale price. As the Government limits total renewables payments through the Levy Control Framework, the perverse effect is to support less renewable electricity, although the EMR was designed to remove obstacles to meeting the renewables target.

Fourth, the commercial case for interconnectors depends on price differences, with GB typically importing from cheaper Continental markets. Lower GB prices reduce arbitrage profits, undermining the investment case for the additional interconnectors when they are increasingly needed to balance growing intermittent generation across wider market areas. Ignoring interconnectors risks a self-fulfilling but expensive policy of autarky.

Fifth, although the future wholesale price will be lower, offsetting possibly a large part of the consumer cost, it will be hard to convince consumers of this. They will see the gross cost, which was estimated at $53.3 \mathrm{GW} \times £ 49 \mathrm{~m} / \mathrm{GWyr}=£ 2.6$ billion per year.

Finally, on $2^{\text {nd }}$ December 2014, after the PTE had published its critical report and the Secretary of State had decided on the procurement volume, but before the auction on $18^{\text {th }}$ December, the Treasury's National Infrastructure Plan announced that interconnectors would be eligible for the 2015 capacity market. ${ }^{13}$ It would have been easy to have left room for interconnectors (e.g. adding another element to the $-w-x-y-z-0.4 \mathrm{GW}$ deductions from the target volume) and lower the net amount to procure.

\subsection{The outcome of the 2014 capacity auction}

The auction cleared at $£(2012) 19.40 / \mathrm{kWyr}$ (National Grid, 2014b). The auction produced several surprises. First, the auction cleared at less than $40 \%$ of the predicted net CONE value of $£ 49 / \mathrm{kWyr}$ (although close to the missing money estimated above assuming a balancing cap of $£ 9,999 / \mathrm{MWh}$ ). The estimated net CONE was based on new entry of CCGT, and two CCGTs entered, supplying about $60 \%$ of the total 2,795 MW new entry. Second, the next largest (28\%) entry category was Open Cycle Gas Turbines (OCGTs)/ reciprocating engines, average size $11 \mathrm{MW}$. The third largest contribution (6\%) was from unproven Demand Side Response (DSR, all with a one-year contract, other new entrants have 15-year contracts).

One might expect that DSR and OCGTs would require a lower strike price, particularly as they can contribute to significantly reducing TNUoS charges if they are

\footnotetext{
${ }^{13}$ See https://www.gov.uk/government/collections/national-infrastructure-plan
} 
embedded with major loads, but the low price that CCGTs were willing to accept is surprising, and may be based on optimistic views of gas prices (which were expected to decline by the time of the auction) or high balancing prices. National Grid announced its tender for new balancing services on 10 June 2014, ${ }^{14}$ reducing the extent of the missing money for these services after DECC had published its estimate of the net CONE.

The final point is that the auction demonstrates the value of market-based methods of revealing entry costs, and the danger of leaving such decisions to SOs or regulators (as in the SEM, ${ }^{15}$ where the regulators calculate the cost of Best New Entry and set it at a high price).

\section{Biases in capacity auctions and energy-only markets}

The arguments above strongly suggest that if procurement decisions are left to politicians advised by the SO, they will err on the high side, and tend to ignore supplies from outside their control area (over interconnectors). Their caution is exacerbated by the emotive and misleading terminology of "Loss of Load". Some of these shortcomings can be addressed by requiring the SO to cost and quantify the actions that are taken in stress events that fall short of controlled disconnections. Delegating the decision to independent agencies, perhaps to an Independent Planning and System Operator could depoliticize the decision (but might not remove the fear of disconnections through inadequacy, nor the bias of not paying for capacity).

There is a more fundamental problem in that if future energy prices are competitively delivered and if all security services (ancillary and balancing) are properly priced, the missing market and missing money problems can both be addressed by offering suitable hedging contracts, of which the auctioned capacity agreement is an excellent example. Price caps could be replaced by reliability options or one-way CfDs that have a high strike price, and which allow consumers or their suppliers to hedge against high prices while allowing the spot and balancing market prices to reach scarcity levels needed for efficient actions (in demand reduction and interconnector trade) (see e.g. Vásquez et al, 2002; Bidwell, 2005).

Now consider the costs of under or over-specifying the amount to procure. Overprocurement, as noted above, risks depressing future prices and hence reducing future energy and ancillary service revenues, requiring a higher auction price in compensation. While addressing the missing markets problem it risks amplifying the missing money problem. In contrast, under-procurement leads to expectations of higher future prices, requiring a lower capacity auction bid as the capacity agreement does not preclude earning revenues in all the energy markets. If the price is very low, investors may conclude that investing without a capacity agreement has relatively low risk, particularly

\footnotetext{
${ }^{14}$ At http://www.nationalgrid.com/uk/electricity/additionalmeasures

${ }^{15}$ See http://www.allislandproject.org/en/cp_current-consultations.aspx?article=75c548a7-34ee497c-afd2-62f8aa0062df
} 
as the design of the GB auction offers a T-4 contract of 15 years for new plant, but successive T-1 contracts of one-year for existing plant at the same clearing price, for which speculative plant would be eligible. A signal to err on the side of underprocurement would be underwritten by the ability to true up closer to delivery, reducing risks, as any over-procurement would merely delay the moment at which more capacity was needed in the auction, and should limit the period of inadequate revenue to a year or so.

\section{Is there a need for regional coordination?}

Eureletric (2015) argues strongly for a design of regional capacity markets which places the obligation on generation (or demand) regardless of national location. This would require a common regional capacity adequacy assessment and no double payment (i.e. if capacity has an agreement from country A it would be denied one from B and would be excluded from B's capacity assessment, subject to adequate interconnector capacity from B to A). As such it may well be suited to the meshed Continental network where power flows according to Kirchoff's Laws, but not necessarily to DC-linked systems.

For markets interconnected over DC links it is not the simplest way of addressing the problem. The underlying problem is that investors lack confidence that they will secure an adequate return. This has two dimensions - future prices may not properly reflect scarcity and other attributes of security, and future prices cannot be hedged and so are risky. Long-term contracts address the latter, efficient short-run pricing the former. Provided the auction platform can accommodate efficient scarcity prices (i.e. provided at least the intra-day and balancing markets are not capped at too low a level), then trading over any interconnector will only benefit a country that ensures that the relevant prices are efficient, as in equation (1). Suppose A and B trade but A has a higher VoLL than B, and hence a larger reliability margin. If A and B both have stress events, A can outbid B to secure imports, with $\mathrm{B}$ accepting a higher LoLP reflecting its lower willingness to pay to avoid disconnections. A can ensure that domestic consumers are insulated from these high trading prices via Reliability Options.

The logic of making adequacy as close as possible to a private market good (through allowing efficient pricing) is that there can be gains from trade for the efficiently priced market even when market designs are different. If prices are inefficient in $\mathrm{B}$, then it is they who lose, not A. That provides incentives to reform and avoids the need for politically fraught agreements on harmonization. The important design question to address is how best to ensure that prices for trading over interconnectors properly reflect scarcity. It may be that a scarcity adder (e.g. the CP in equation (1) or an amount to bring the supply schedule up to the full price in (1)) must be administratively added, or there may be other ways in which the SO can ensure that the trading country acquires all it needs up to the VoLL before controlled disconnections, but such design issues can be devolved to Member States (MSs). 
The most important EU-level issue is to ensure that MSs cannot invoke security of supply as a reason for arbitrary interventions in the free flow of electricity across borders. The present arrangements are governed by the Security of Supply Directive (2005/89/EC), ${ }^{16}$ but there are concerns that political imperatives could over-ride market outcomes or those set out in SO to SO agreements as to what should happen in simultaneous stress events in which the auction allocation mechanism fails (perhaps because it has reached its price cap). If the goal of European market integration is to be achieved, MSs must be confident that they can secure supplies up to their VoLL, in return for which they should be willing to offer supplies to other MS at prices above their local VoLL, without arbitrary interventions.

That leaves the question of how to deal with the case in which MS A places the capacity obligation on the interconnector owner (as will be the case in Britain) while MS $B$ places the obligation on generators, some of whom are located in A. This could be handled by barring such generators from any capacity agreements in A, and requiring $B$ to buy back the associated volume of interconnector capacity from the interconnector owner, with the agreement stating that if the auction prices reach the caps or the market coupling ceases to allocate in a stress situation in B, then that volume of imports by $\mathrm{B}$ will be assured. As such it can be devolved to bilateral agreements.

\section{Conclusions and policy implications}

Missing money and missing markets provide compelling reasons for a capacity payment in competitive electricity markets dominated by politically determined and subsidized unreliable generation and where investors lack confidence in future revenues. Some countries may have surplus capacity and may be under no immediate pressure to encourage new investment, and can defer addressing these questions, but many countries will find a need to encourage efficient investment if only to address increasing intermittent renewables penetration. It may be that well-designed markets can secure the required flexible capacity but it is more likely that tender auctions/contracts will also be needed, and these have much in common with capacity auctions.

Capacity auctions (GB provides a good example) address the missing money problem and part of the missing market problem (the missing futures markets). Other signals for location, flexibility, etc. needed to deliver security still need efficient solutions, which may be best supplied by markets, auctions or procurement contracts. The part of the adequacy debate that has been neglected is how to, and who should, determine the amount and type of capacity to procure (generation, DSR, interconnection), a problem that is exacerbated by misunderstandings over what a "Loss of Load" event means and what it might cost.

This paper argues that this neglect biases towards over-procurement, which leads to a self-fulfilling prophecy that merchant generation investment can no longer be relied

${ }^{16}$ At http://eur-lex.europa.eu/legal-content/EN/TXT/?uri=URISERV:127016 
upon. Perversely, this exacerbates the missing money problem that capacity auctions were designed to address. The bias is further exacerbated by failing to address some of the missing market problems that have also been neglected in the debate.

Whether or not interconnectors should be included in auctions is less important than that their contribution should be recognized in determining the procurement amount. All British interconnectors are HVDC controllable links whose flows can be rapidly reversed and as such could provide extra imports at short notice. The UK Government, possibly under pressure from DG COMP over State Aid concerns after the PTE had published their criticisms (DECC, 2014a), decided to include interconnectors in the next auction for 2019-20 delivery, and consult on how to determine their reliable capacity.

There remain a number of policy issues to resolve, not least how the European auction platform EUPHEMIA will determine the direction of flows close to real time, when stress events that the capacity auction was designed to address are likely to emerge. EUPHEMIA has a $€ 3,000 / M W h$ price cap on the DAM, well below the VoLL. It has not yet (mid-2015) fixed price caps for intra-day and balancing actions, nor are these markets yet fully operational. If prices in the real time European markets could properly reflect scarcity, and if each Member State's market could deliver the true scarcity prices to EUPHEMIA (including the CP of equation (1)) then good market design and pricing would deliver efficient solutions, and other countries with less good pricing would lose out, motivating them to improve their market design.

Price caps hinder this aim, and instead good rules will be needed for out-ofmarket actions when price caps are reached, and/or markets no longer determine flows, and SOs have to intervene. These rules or bilateral agreements between the SOs at each end of interconnectors are currently lacking or incomplete and may need to be addressed through a revised Security of Supply Directive, and in the meantime by carefully designed SO to SO agreements, overseen by the relevant MS regulators (and possibly by the European Commission if they may adversely impact other trade flows). If these problems can be addressed, then the more demanding task of harmonizing regional capacity markets may be unnecessary and individual MSs can design their own Capacity Mechanisms, drawing on the GB and other experiences. 


\section{References}

Adib, P., Schubert, E., Oren, S., 2008. Resource Adequacy: Alternate Perspectives and Divergent Paths, in Sioshansi, F. P., (Ed.), Competitive Electricity Markets: Design, Implementation, Performance. Oxford: Elsevier. Pp. 327-362. http://dx.doi.org/10.1016/B978-008047172-3.50013-1 .

Bates, R., Fraser, N., 1974. Investment Decisions in the Nationalised Fuel Industries, Cambridge, CUP.

Batlle, C., Vazquez, C., Rivier, M., Perez-Arriaga, I.J., 2007. Enhancing Power Supply Adequacy in Spain: Migrating from Capacity Payments to Reliability Options. Energy Policy 35(9): 4545-4554. http://dx.doi.org/10.1016/j.enpol.2007.04.002 .

Battle, C. Rodilla, P., 2010. A critical assessment of the different approaches aimed to secure electricity generation supply. Energy Policy 38, 7169-7179. doi: 10.1016/j.enpol.2010.07.039.

Bidwell, M., 2005. Reliability Options: A Market-Oriented Approach to Long-Term Adequacy. The Electricity Journal, 185, 11-25.

Bompard, E., Huang, T., Wu, Y., Cremenescu, M., 2013. Classification and trend analysis of threats origins to the security of power systems. Int. J. of Elec. Power \& Energy Systems, 50, 50-64, ISSN 0142-0615, http://dx.doi.org/10.1016/j.ijepes.2013.02.008 .

Bowring, J., 2008. The evolution on PJM's capacity market, ch 10 in Sioshansi, F.P. (ed.), Competitive Electricity Markets: Design, Implementation, Performance. Elsevier, pp. 363-386.

Bowring, J., 2013. Capacity Markets in PJM. Econ. of Energy and Envir. Pol., 22. 47-64.

Chao, H.P., Wilson, R., 1987. Priority Service: Pricing, Investment and Market Organization. American Economic Review, 77(5): 89-116.

Chao, H.P. Wilson, R., 2002. Multi-Dimensional Procurement Auctions for Power Reserves: Robust Incentive-Compatible Scoring and Settlement Rules. J. Reg. Econ., 22(2): 161183. http://dx.doi.org/10.1023/A:1020535511537

Cramton, P. Ockenfels, A., 2011. Economics and Design of Capacity Markets for the Power Sector, at http://www.cramton.umd.edu/papers2010-2014/cramton-ockenfels-economicsand-design-of-capacity-markets.pdf (published in 2012 in Zeitschrift für Energiewirtschaft, 36(2): 113-134).

Cramton, P. Stoft, S., 2008. Forward reliability markets: less risk, less market power, more efficiency. Util. Pol., 16(3): 194-201. http://dx.doi.org/10.1016/j.jup.2008.01.007

Cramton, P., Ockenfels, A., Stoft, S., 2013. Capacity Market Fundamentals. Econ..Energy and Envir. Pol., 22. 27-46.

DECC, 2009. The UK Low Carbon Transition Plan, at https://www.gov.uk/government/uploads/system/uploads/attachment_data/file/228752/97 $\underline{\text { 80108508394.pdf }}$

DECC, 2010. Electricity Market Reform: A consultation document. HMG Dec, at http://www.decc.gov.uk/en/content/cms/consultations/emr/emr.aspx accessed 22.03.13

DECC, 2014a. EMR Panel of Technical Experts Final Report on National Grid’s Electricity Capacity Report, at https://www.gov.uk/government/uploads/system/uploads/attachment_data/file/252743/Ca pacity_Market_Impact_Assessment_Oct_2013.pdf 
DECC, 2014b. Impact Assessment June 2014, at https://www.gov.uk/government/uploads/system/uploads/attachment_data/file/324430/Fi nal_Capacity_Market_Impact_Assessment.pdf

DECC, 2014c. Implementing Electricity Market Reform (EMR): Finalised policy positions for implementation of EMR, June, at https://www.gov.uk/government/uploads/system/uploads/attachment_data/file/324176/Im plementing_Electricity_Market_Reform.pdf accessed 25.8.15

DECC, 2015. Historical electricity data: 1920 to 2014, at https://www.gov.uk/government/statistical-data-sets/historical-electricity-data-1920-to2011 updated 2015, accessed 24.8.15

ENTSO-E, 2015. Metadata repository. Glossary of terms, statistical glossary. https://emr.entsoe.eu/glossary/bin/view/GlossaryCode/GlossaryIndex accessed 31/3/15

Eurelectric, 2015. A Reference Model For European Capacity Markets, March at http://www.eurelectric.org/media/169068/a_reference_model_for_european_capacity_ma rkets-2015-030-0145-01-e.pdf

Green, R.J., Newbery, D.M., 1992. Competition in the British Electricity Spot Market. J.P. E., 1005, 929-53.

HM Treasury, Budget 2011, HC 836, March 2011

Joskow, P.L., 2008. Capacity Payments in Imperfect Electricity Markets: Need and Design. Util. Pol., 163, 159-70. http://dx.doi.org/10.1016/j.jup.2007.10.003 .

Joskow, P., 2013. Symposium on Capacity Markets. Econ. Energy and Envir. Pol., 22. v-vi.

Joskow, P.L. Tirole, J., 2007. Reliability and Competitive Electricity Markets. Rand J Econ., 381, 68-84. http://dx.doi.org/10.1111/j.1756-2171.2007.tb00044.x .

London Economics, 2013. The Value of Lost Load VoLL for Electricity in Great Britain; Final report for OFGEM and DECC, July, at https://www.gov.uk/government/uploads/system/uploads/attachment_data/file/224028/va lue lost load electricty gb.pdf

Mott MacDonald, 2013. Impact Assessment on European Electricity Balancing Market, at http://ec.europa.eu/energy/gas electricity/studies/doc/electricity/20130610_eu_balancing _master.pdf

National Grid, 2013. TNUoS tariffs for 2013/14. January, at http://www2.nationalgrid.com/UK/Industry-information/System-charges/Electricitytransmission/Approval-conditions/Condition-5/

National Grid, 2014a. Electricity Capacity Report, at http://www2.nationalgrid.com/UK/Our\%20company/Electricity/Market\%20Reform/Ann ouncements/June\%202014\%20Auction\%20Guidelines\%20publication/

National Grid, 2014b. Provisional Auction Results: T-4 Capacity Market Auction 2014, at https://www.gov.uk/government/uploads/system/uploads/attachment_data/file/389832/Pr ovisional_Results_Report-Ammendment.pdf

NERC, 2015. Glossary of Terms Used in NERC Reliability Standards, at http://www.nerc.com/files/glossary of terms.pdf

Newbery, D.M., 1989. Missing Markets: Consequences and Remedies, ch 10, in Economics of Missing Markets, Information, and Games, F.H. Hahn ed., Clarendon Press, Oxford, pp. 211-42. 
Newbery, D. M., 1995. `Power Markets and Market Power. The Energy Journal, 163, 41-66.

Newbery, D.M., 2005. Electricity liberalisation in Britain: the quest for a satisfactory wholesale market design. Energy Journal, Special Issue on European Electricity Liberalisation, ed. D Newbery, 43-70 at http://www.iaee.org/en/publications/speciali.aspx

Newbery, D.M., 2010. Market design for a large share of wind power. Energy Policy, 387, 31313134, at http://dx.doi.org/10.1016/j.enpol.2009.07.037

Newbery, D.M., 2012a. Reforming Competitive Electricity Markets to Meet Environmental Targets. Econ. Energy \& Envir. Pol. 11, 69-82.

Newbery, D.M., 2012b. Contracting for wind generation. Econ. Energy \& Envir. Pol., 12.19-36.

Newbery, D.M., 2013. Evolution of British electricity market and the role of policy for the regulation toward low carbon future, in: Sioshansi, F. P. (Ed.), Evolution of Global Electricity Markets: New paradigms, new challenges, new approaches, Elsevier, pp3-33.

Newbery, D.M. and Grubb, M., 2015. Security of Supply, the Role of Interconnectors and Option values: Insights from the GB Capacity Auction. Econ. Energy \& Envir. Pol. in press.

Ofgem, 2010. Project Discovery: Options for delivering secure and sustainable energy supplies, at https://www.ofgem.gov.uk/ofgempublications/40354/projectdiscoveryfebcondocfinal.pdf

Ofgem, 2014. Electricity Capacity Assessment Report 2014, at https:/www.ofgem.gov.uk/sites/default/files/docs/2014/06/electricity capacity assessme nt 2014 _ full_report final_for_publication.pdf accessed 24.8.15

O'Neill, R., Helman, U., Hobbs, B. F., Baldick, R. 2006. Independent System Operators in the USA: History, Lessons Learned and Prospects, in: Sioshansi, F.P., Pfaffenberger, W., (Eds.), Electricity Market Reform: An International Perspective, Amsterdam: Elsevier, ISBN13 978-0-08045-030-8, pp. 479-528.

Oren, S., 2000. Capacity Payments and Supply Adequacy in a Competitive Electricity Market, paper presented at VII SEPOPE, Curitiba-Parana Brazil, May 21-26, at www.ieor.berkeley.edu/ oren/workingp/sepope.pdf

Platchkov, L., Pollitt, M., Shaorshadze, I., 2011. The implications of recent UK energy policy for the consumer: A report for the Consumers' Association, at http://www.eprg.group.cam.ac.uk/tag/l-platchkov/

Pöyry, 2012. IMPACT OF EMR ON INTERCONNECTION: A report to Department of Energy and Climate Change 3 Dec 2012, at https://www.gov.uk/government/uploads/system/uploads/attachment_data/file/252744/Po yry Report on_Impact of CM on_Interconnection.pdf

Pöyry, 2013. Analysis of the Correlation of Stress Periods in the Electricity Markets in GB and its Interconnected Systems: A report to Ofgem, March 2013 at https://www.ofgem.gov.uk/ofgem-publications/75231/poyry-analysis-correlation-tightperiods-electricity-markets-gb-and-its-interconnected-systems.pdf

Pöyry, 2014. Revealing the Value of Flexibility: How can flexible capability be rewarded in the electricity markets of the future?, at http://www.poyry.com/sites/default/files/imce/files/revealing the value of flexibility_p ublic_report_v1_0.pdf

Redpoint, 2013. Impacts of further electricity interconnection on Great Britain, at https:/www.gov.uk/government/uploads/system/uploads/attachment_data/file/266307/D 
ECC Impacts of further electricity interconnection for GB Redpoint Report Final.p $\underline{\mathrm{df}}$

Roques, F. A., Nuttall, W.J., Newbery, D. M., de Neufville, R., Connors, S., 2006. Nuclear Power: a Hedge against Uncertain Gas and Carbon Prices? The Energy Journal, 27, 4, 124, at http://www.iaee.org/en/publications/ejarticle.aspx?id=2155

Roques, F.A., Newbery, D. M., and Nuttall, W. J., 2008. Fuel mix diversification incentives in liberalized electricity markets: a Mean-Variance Portfolio Theory Approach. Energy Economics, 30/4, 1831-1849.

SEM, 2007. The Bidding Code of Practice - A Response and Decision Paper. 30 July 2007, AIPSEM-07-430, at www.allislandproject.org

SEM, 2014. DS3 System Services - Procurement Consultation - Final. at http://www.allislandproject.org/en/transmission_current_consultations.aspx?article=11d5 5fa2-e9cd-454c-aaa5-d689d434db20\&mode=author

Sweeting, A., 2007. Market Power in the England and Wales Wholesale Electricity Market 19952000. The Econ. J., 117: 654-685. doi: 10.1111/j.1468-0297.2007.02045.

Vázquez, C., Rivier, M., Pérez-Arriaga, I. J., 2002. A market approach to long-term security of supply. IEEE Transactions on Power Systems, 17 2: 349-357.

de Vries L.J., 2007. Generation adequacy: helping the market to do its job, Util. Pol., 15, 20-35. Doi:10.1016/j.jup/2006.08.001

Webb, M. G., 1977. The determination of reserve generating capacity criteria in electricity supply systems. Appl. Econ., 9, 19-21.

Williams, E., 1991. Dinorwig: The electric mountain, London: National Grid 